\title{
Individual Differences in Vulnerability to Sleep Loss in the Work Environment
}

\author{
Hans P.A. VAN DONGEN ${ }^{1 *}$ and Gregory BELENKY ${ }^{1}$ \\ ${ }^{1}$ Sleep and Performance Research Center, Washington State University Spokane, P.O. Box 1495, Spokane, \\ WA 99210, USA
}

Received May 4, 2009 and accepted June 5, 2009

\begin{abstract}
There are considerable individual differences in cognitive performance deficits resulting from extended work hours and shift work schedules. Recent progress in sleep and performance research has yielded new insights into the causes and consequences of these individual differences. Neurobiological processes of sleep/wake regulation underlie trait individual variability in vulnerability to performance impairment due to sleep loss. Trait vulnerability to sleep loss is observed in the laboratory and in the work environment, even in occupational settings where (self-)selection pressures are high. In general, individuals do not seem to accurately assess the magnitude of their own vulnerability. Methods for identifying workers who are most at risk of sleep loss-related errors and accidents would therefore be helpful to target fatigue countermeasure interventions at those needing them most. As yet, no reliable predictors of vulnerability to sleep loss have been identified, although candidate genetic predictors have been proposed. However, a Bayesian forecasting technique based on closed-loop feedback of measured performance has been developed for individualized prediction of future performance impairment during ongoing operations. Judiciously selecting or monitoring individuals in specific tasks or occupations, within legally and ethically acceptable boundaries, has the potential to improve operational performance and productivity, reduce errors and accidents, and save lives. Trait individual variability in responses to sleep loss represents a major complication in the application of one-size-fits-all hours of service regulations-favoring instead modern fatigue risk management strategies, because these allow flexibility to account for individual vulnerability or resilience to the performance consequences of extended work hours and shift work schedules.
\end{abstract}

Key words: Cognitive performance, Differential vulnerability, Fatigue, Job selection, Occupational settings, Safety risk, Shift work, Sleep deprivation

\section{Introduction}

It has long been recognized that individuals differ markedly in their responses to extended work hours ${ }^{1-6)}$ and shift work schedules ${ }^{7-9)}$. Research in this area focused initially on demographics, behavioral patterns and external circumstances as factors explaining and predicting these individual differences, but with limited success $^{10)}$. More recently, the emphasis shifted to the endogenous neurobiology underlying sleep/wake regulation and 24-h (circadian) rhythm ${ }^{10,11)}$. This line of research gained impetus due to a study showing that there are substantial individual differences in performance impairment resulting from sleep deprivation, and demonstrating that these individual differences constitute a trait ${ }^{12)}$. In this paper, we discuss the trait individual differences in performance impairment due to sleep loss, and consider their relevance in operational environments. We also examine ways to predict the individual differences in vulnerability to sleep loss, and reflect on the legal and ethical implications of doing so in occupational settings.

*To whom correspondence should be addressed.

E-mail: hvd@wsu.edu 


\section{Trait individual differences in performance impairment due to sleep loss}

Broad recognition of the existence of considerable, neurobiologically mediated individual differences in performance impairment resulting from sleep deprivation followed from a study designed specifically to investigate this issue ${ }^{12)}$. In a laboratory environment with a high degree of experimental control, a total of 21 healthy adults (ages 21-38; 12 men, 9 women) were subjected to $36 \mathrm{~h}$ of total sleep deprivation on three separate occasions. In the week prior to each sleep deprivation session, the subjects either restricted their sleep to $6 \mathrm{~h}$ per day (prior sleep restriction condition) or extend their time in bed for sleep to $12 \mathrm{~h}$ per day (prior sleep satiation condition). The prior sleep restriction condition occurred only once, in randomized, counterbalanced order.

During each laboratory sleep deprivation session, a battery of subjective sleepiness measures and cognitive performance tests was administered every $2 \mathrm{~h}$. This battery included the Karolinska sleepiness scale (KSS) ${ }^{13}$, a word detection test (WDT) $)^{2}$, and a psychomotor vigilance test $(\mathrm{PVT})^{14)}$, among other tasks. The KSS is a Likert-type scale ranging from 1 (very alert) to 9 (very sleepy). The WDT is a signal detection task requiring identification of a 5-letter word presented among a series of 5-letter nonwords of the same form (consonant-vowel-consonantvowel-consonant). The PVT is a widely used sustainedattention reaction time task with high signal load, of which a 20-min version was administered. Outcome measures included the subjective sleepiness score on the KSS, the number of correct responses on the WDT, and the number of lapses (reaction times $\geq 500 \mathrm{~ms}$ ) on the PVT. These outcome measures were averaged over the last $24 \mathrm{~h}$ (i.e., one circadian cycle) of each 36-h sleep deprivation period, in order to obtain estimates of impairment due to sleep loss.

The observed levels of sleepiness and performance during each of the three sleep deprivation sessions are shown for each individual subject in Fig. 1. For every outcome measure, there was wide variability among individuals. However, within each subject, the responses to sleep deprivation were very similar for the two sleep deprivation sessions with prior sleep satiation. The percentage of variance explained by replicable individual differences was $90.4 \%$ for the KSS, $92.2 \%$ for the WDT, and $67.5 \%$ for the PVT. Similarly high percentages were found for other outcome measures examined in the study ${ }^{12}$. The individual differences persisted when baseline individual differences in sleepiness and performance were taken into account. Moreover, in the sleep deprivation session with prior sleep restriction, the subjects' individual responses were also similar to those observed in the prior sleep sati- ation condition. Thus, not only were the effects of sleep deprivation on sleepiness and performance highly replicable, they also were robust to manipulation of sleep history. This latter finding casts doubt on a recent claim that trait vulnerability to sleep loss may be partially or entirely explained by how much sleep is habitually obtained $^{15)}$ rather than by how much sleep loss can be tolerated.

The findings of the study described above could be summarized as follows. (1) There were individual differences in sleepiness and performance impairment due to sleep deprivation. (2) These individual differences were substantial, both in absolute magnitude and relative to the group-average effects of sleep deprivation. (3) The individual differences were highly replicable over repeated exposures to sleep deprivation. (4) The individual differences in responses to sleep deprivation were not predicted by baseline differences among individuals. (5) The individual differences were preserved across experimental manipulations of prior sleep history (i.e., they were robust). From these findings, it was concluded that vulnerability to performance impairment due to sleep deprivation constitutes a trait ${ }^{12)}$.

The trait of vulnerability to sleep loss is not the only neurobiological source of individual variability that determines people's responses to extended wakefulness and shift work. Two distinct neurobiological processes play an important role in determining the temporal profile of performance responses to extended and shifted work times. These are the homeostatic process, which builds up a pressure for sleep across time spent awake and dissipates that pressure across time spent asleep; and the circadian process, which yields an opposing pressure for wakefulness during the day and withdraws that pressure at night ${ }^{16-18)}$. As illustrated in Fig. 2, these processes interact and produce dynamic changes in sleepiness and performance over time. Furthermore, they affect the timing and duration of sleep and thereby exert indirect influence on sleepiness and performance as well. Indeed, the typical shift worker is forced to work at times that are suboptimal for good performance, and go to bed at times that are suboptimal for good sleep ${ }^{11)}$.

Given the involvement of two interacting processes, other neurobiological traits besides vulnerability to sleep loss are likely to contribute to individual differences in responses to extended work hours and shift work (as shown in the right panel of Fig. 2, neither process alone is fully responsible for the individual variability in performance). These traits may include individual differences in sleep need, recovery rate during sleep following sleep deprivation, circadian timing (phase), circadian amplitude, and rate of circadian adjustment to schedule changes ${ }^{19)}$. Of those, only the individual variability in 

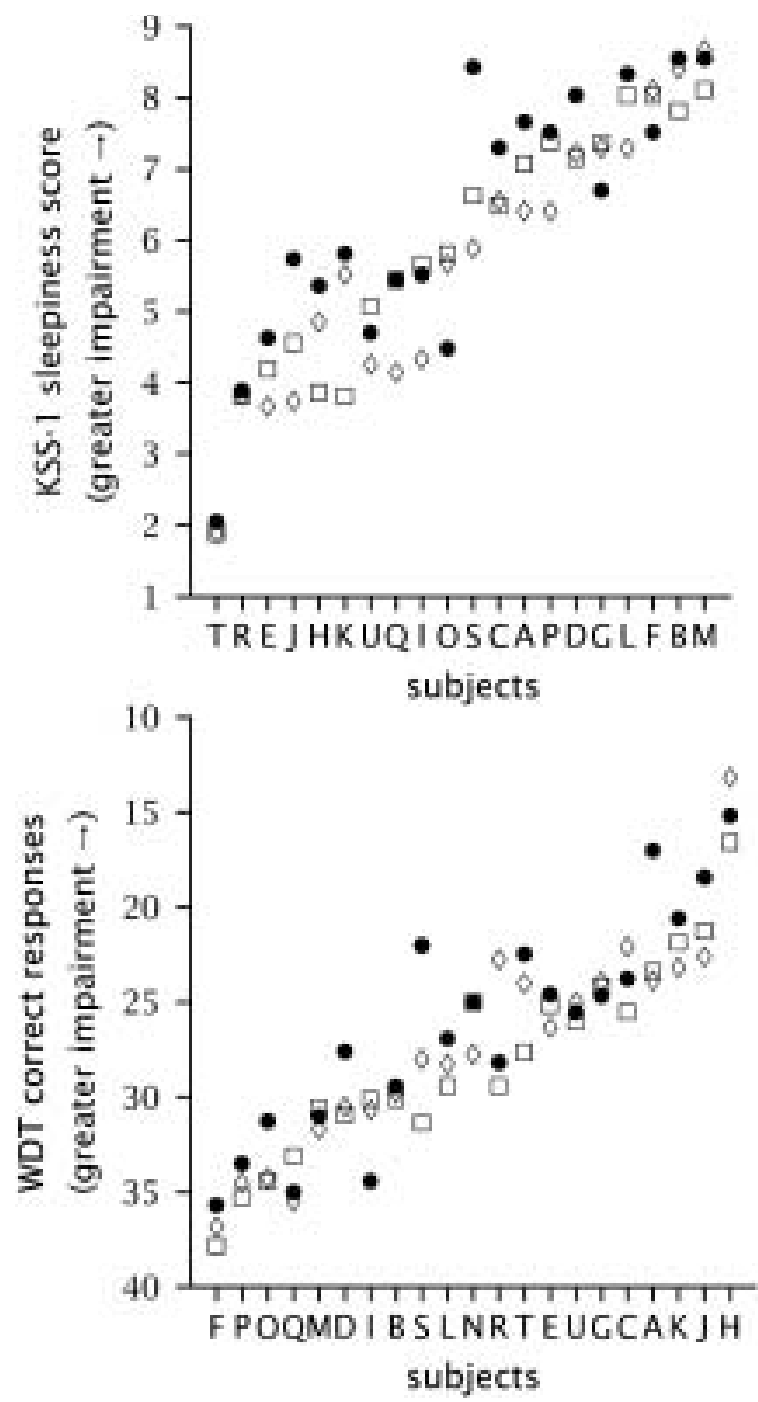

Fig. 1. Individual subjects' sleepiness and performance responses to $36 \mathrm{~h}$ of total sleep deprivation, as expressed by averages over the last $24 \mathrm{~h}$ of sleep deprivation. The graphs show the individuals' responses in three separate laboratory exposures to total sleep deprivation. Two sleep deprivation sessions were preceded by $7 \mathrm{~d}$ of sleep extension to $12 \mathrm{~h}$ time in

circadian phase position has been studied extensive$1 y^{20,21)}$ - it gives rise to the trait of morningness/eveningness $^{22)}$ and has been recognized to be involved in tolerance for shift work ${ }^{23,24)}$. Much more research is needed to uncover the full range of endogenous factors that may play a role ${ }^{19}$.

\section{Individual differences in vulnerability to sleep loss in occupational settings}

While systematic individual differences in vulnerability to sleepiness and performance impairment due to sleep loss have been documented in laboratory stud-

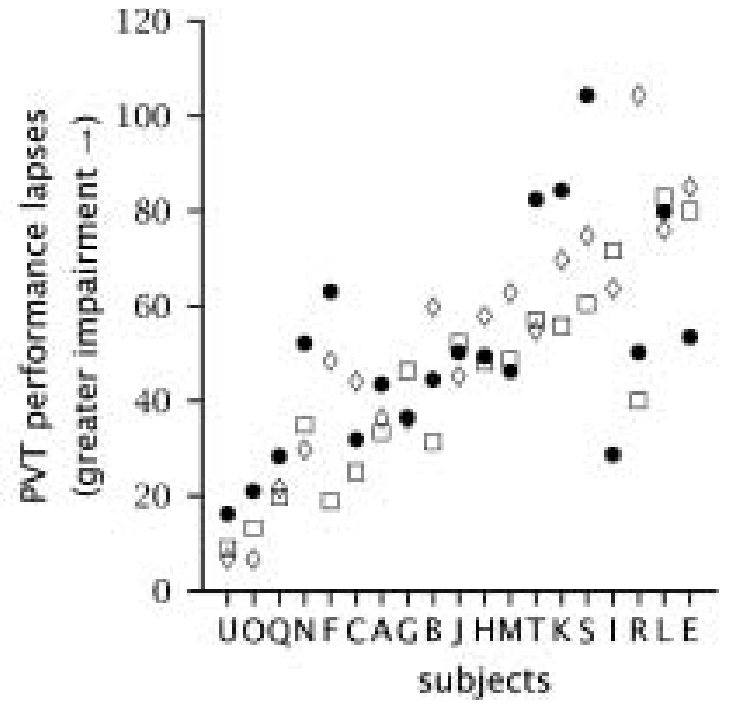

bed per day (white boxes and diamonds), whereas one sleep deprivation session was preceded by $7 \mathrm{~d}$ of sleep restriction to $6 \mathrm{~h}$ time in bed per day (black circles). Data are shown for the Karolinska sleepiness scale administered at the beginning of each test bout (KSS-1), for a word detection task (WDT), and for a psychomotor vigilance task (PVT). The abscissa of each graph shows 21 individual subjects labeled A through U, with the same label being used for the same subject across panels (data were incomplete in 1 subject for the KSS and in 2 subjects for the PVT). Within each graph, the subjects are ordered by the magnitude of their impairment (averaged over the two sleep deprivations preceded by sleep extension), with the most resistant subjects on the left and the most vulnerable subjects on the right. The graphs reveal that subjects differed substantially in their responses to sleep deprivation, and that these responses were stable within subjects across repeated exposures to sleep deprivation regardless of prior conditions. Note also that the order of the subjects varied between outcome measures, as discussed in the main text. Figure taken from Van Dongen et al. (2004) ${ }^{12)}$ with permission.

ies $^{5,12,25,26)}$, the implications thereof in real-world operational settings cannot be readily inferred. For instance, (self-)selection processes may result in workers distributing over occupations and shift schedules that are least challenging for them. To probe this issue, Caldwell and colleagues investigated whether systematic individual differences in vulnerability to sleep loss can still be observed among a highly selected population of U.S. Air Force fighter pilots ${ }^{27}$. Ten active-duty F-117 "Nighthawk" stealth fighter pilots were deprived of sleep for $38 \mathrm{~h}$ and studied repeatedly in a high-fidelity flight simulator. Systematic individual differences in the effects of sleep deprivation on performance were observed in a variety of 

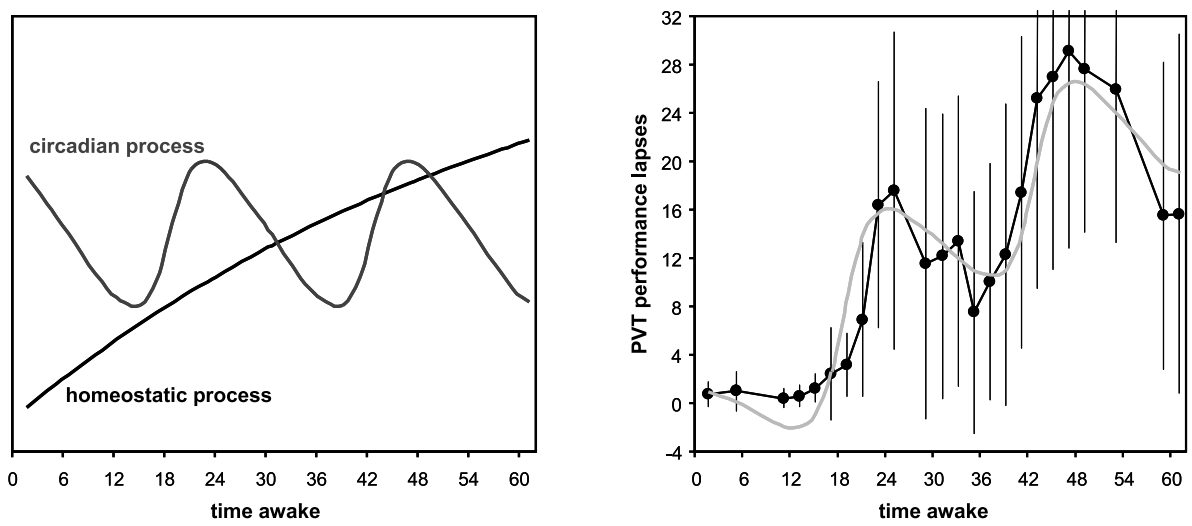

Fig. 2. Dynamic influences on cognitive performance by two key neurobiological processes: a homeostatic process and a circadian process. The left panel shows a gradual increase of the homeostatic process across $62 \mathrm{~h}$ of total sleep deprivation, representing the progressive build-up of pressure for sleep over time awake; and an oscillatory pattern of the circadian process with a period of (approximately) $24 \mathrm{~h}$, representing the waxing and waning of pressure for wakefulness over time of day (curves derived from published mathematical equations ${ }^{60)}$ ). The right panel shows the sum of these two influences as a model of performance impairment (gray curve), superimposed on actual measurements of performance during $62 \mathrm{~h}$ of total sleep deprivation in a laboratory (black curve). The data shown in the right panel are averages (black circles) with one standard deviation on each side (whiskers) over 12 healthy adults (ages 22-37; 7 men, 5 women). The model curve matches the performance averages well. However, variability due to systematic individual differences (not accounted for by the model) is considerable after the first day of wakefulness.

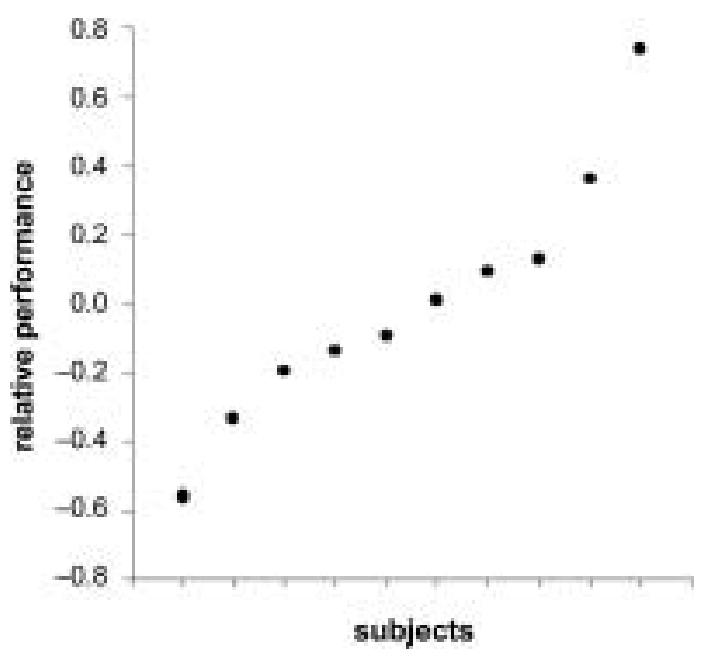

Fig. 3. Individual fighter pilots' average performance on a $720^{\circ}$ left turn in a high-fidelity F-117 flight simulator, as measured every $5 \mathrm{~h}$ during the night and subsequent day of a period of $38 \mathrm{~h}$ of total sleep deprivation. Tick marks on the abscissa represent 10 individual pilots, ordered by the magnitude of their performance impairment (the pilots most resistant to sleep deprivation are on the left). The ordinate shows the pilots' average performance on the flight maneuver in terms of roll accuracy, expressed relative to each other, after correcting for baseline differences. Systematic individual differences accounted for $58 \%$ of the variance in the data ${ }^{27}$.

flight maneuvers, as illustrated in Fig. 3.

This finding suggests that selection and self-selection mechanisms cannot be counted upon to eliminate indi- vidual differences in vulnerability to sleep loss from the work force, even for highly demanding professions in which extended work hours and circadian dysregulation are commonplace and selection pressures are high. Of course, for people to be able to self-select out of operational settings that put them at excessive risk of performance impairment and reduced safety, they have to be aware of their vulnerability. Evidence suggests that this is not consistently the case. Individual differences in the effects of sleep loss on subjective measures of sleepiness are not congruent with individual differences in the effects of sleep loss on objective measures of performance ${ }^{5,12,28)}$. This can be seen in Fig. 1, where subjects are ranked by the magnitude of their impairment-the order of subjects is considerably different between the top left panel (subjective sleepiness) and the other two panels (objective performance). A consequence of this discrepancy is illustrated in Fig. 4: it appears that individuals cannot be relied upon to accurately self-estimate their vulnerability to performance impairment due to sleep loss.

It is not clear whether individual differences in performance impairment due to sleep loss as observed on one task are predictive of individual differences in performance impairment on another task (and by extension, whether individual differences in performance impairment due to sleep loss transfer from one occupation to another). Van Dongen and colleagues found preliminary evidence that during sleep deprivation, individual differences 

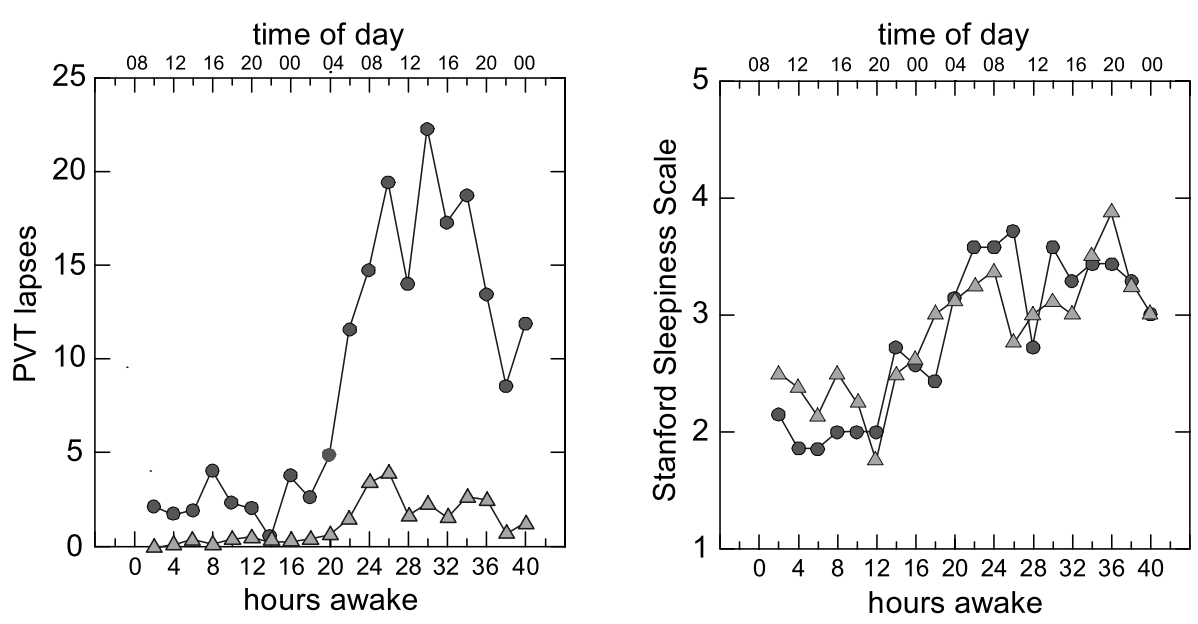

Fig. 4. Discrepancy between individual differences in objective performance and individual differences in subjective sleepiness during $40 \mathrm{~h}$ of total sleep deprivation in a laboratory. A sample of 24 subjects was divided into three subgroups based on the magnitude of their performance impairment during sleep deprivation, as quantified by the number of lapses (reaction times $\geq 500 \mathrm{~ms}$ ) on a 10-min psychomotor vigilance test (PVT). Triangles show data from the 8 subjects least affected by sleep deprivation, and circles show data from the 7 subjects most affected by sleep deprivation (the intermediate subgroup is not shown). The differences in PVT impairment between the least affected and most affected subgroups were substantial (left panel). However, no significant differences in subjective sleepiness on the Stanford sleepiness scale were found between these two subgroups (right panel). Thus, self-reported sleepiness did not accurately reflect the objective performance deficits that differentiated individuals in their responses to sleep deprivation. Figure adapted from Van Dongen et al. $(2004)^{61)}$ with permission.

on the 20-min version of the PVT were unrelated to individual differences on other performance tasks such as the WDT $^{12)}$. This is illustrated in Fig. 1: the order of subjects in the bottom left panel (WDT) is different from that in the right panel (PVT). Of the five performance tasks examined in the study, four tasks including the WDT showed a clustering of individual differences-those who were most vulnerable on the WDT were also most vulnerable on the other tasks in this cluster. The PVT stood apart, showing a distribution of individual differences that was independent of performance on the other tasks. It has been hypothesized that this dissociation is related specifically to the sustained attention required to perform the 20-min PVT. Tentative support for this hypothesis comes from the high-fidelity flight simulator study of U.S. Air Force fighter pilots. Here, individual variability in performance on the $720^{\circ}$ left turn (Fig. 3), which was the maneuver with the greatest sustained attention demand, was orthogonal to individual variability seen during other flight maneuvers. More work is needed to confirm and understand these findings.

People also differ significantly from each other in responses to fatigue countermeasures. There are well documented individual differences in sensitivity to caffeine ${ }^{29,30)}$. Individual variability has also been reported for the fatigue-mitigating effects of modafinil ${ }^{31)}$, which is another wake-promoting substance ${ }^{32}$. There is a scarci- ty of knowledge about variability among individuals in the effectiveness of napping as a fatigue countermeasure ${ }^{33)}$, and in susceptibility to sleep inertia (cognitive performance impairment and grogginess) immediately after a nap. More research on individual differences in fatigue countermeasure effectiveness should be a priority, to be added to a recently proposed agenda for individual differences research ${ }^{19}$.

Those who suffer the greatest consequences of extended work hours and shift work schedules also have the greatest potential to benefit from countermeasure usethus, individual variability in countermeasure effectiveness is at least partially related to individual variability in vulnerability to sleep loss. However, vulnerability to sleep loss may result from a variety of underlying mechanisms, which may be differentially affected by the various pharmacological countermeasures ${ }^{34)}$. As such, studying individual differences in responses to pharmacological countermeasures of fatigue would exemplify Pasteur's quadrant of use-inspired basic research ${ }^{35)}$, having both basic and applied significance.

\section{Predicting individual differences in vulnerability to sleep loss}

There could be considerable benefit to accurately predicting who is vulnerable to the adverse effects of sleep 
loss and who is resilient ${ }^{36)}$. It has been pointed out that a relatively small portion of individuals may account for most of the risk posed by occupational fatigue ${ }^{37}$. In safety-sensitive operations, reliable identification of workers who are most at risk of errors and accidents due to sleep loss would allow targeted application of fatigue countermeasures or removal of these individuals from harm's way. For this and other reasons, after the trait of vulnerability to sleep loss had been established ${ }^{12)}$, a broad search for predictors of this trait ensued.

Examination of demographics, baseline cognitive functioning, sleep traits and habits, circadian rhythm profiles, standard clinical outcomes of blood and urine chemistry, and psychological traits such as personality has yielded no viable candidate predictors of vulnerability ${ }^{10,12)}$. Even the impact of age in the range commonly encountered in the work environment (examined specifically in the range from 24 to 62$)^{38)}$ appears to be relatively minor. Sleep disorders and other clinical conditions can put individuals at elevated risk of performance impairment during sleep deprivation, but variability among individuals in the degree of impairment due to sleep loss may nevertheless be substantial ${ }^{39,40)}$.

In two retrospective studies, it was found that individuals with comparatively low baseline levels of global brain activation, as measured with functional magnetic resonance imaging (fMRI), were more vulnerable to the effects of sleep deprivation on a working memory $\operatorname{task}^{28,41)}$. However, the interpretation of this finding is complicated by a number of methodological issues and possible confounds ${ }^{42)}$, and the practical utility of fMRIbased measures for predicting vulnerability to sleep loss in operational environments is limited.

Potentially more promising is the discovery of genetic predictors of responsiveness to sleep deprivation ${ }^{43,44)}$. These include polymorphisms involved in the regulation of neurotransmitters (catechol-O-methyltransferase) ${ }^{31)}$, brain metabolism (adenosine receptor and adenosine deaminase) ${ }^{45,46)}$, and circadian rhythmicity (the clock gene PER3 $)^{47)}$. Studies of genetic predictors have typically involved comparison of groups selected a priori to differ by the polymorphism under consideration. Consequently, it remains unknown how much of the between-subjects variance in responses to sleep loss these genetic predictors can explain in the general population. At this time, therefore, the usefulness of genetic predictors of vulnerability to performance impairment due to sleep loss has yet to be determined.

In the absence of baseline predictors, it would still be possible to subject individuals to sleep deprivation and simply measure their cognitive impairment (under controlled circumstances to minimize interference from irrelevant sources of variance) - thereby determining their vul- nerability to sleep loss directly. Since vulnerability constitutes a trait, the results should be predictive of the individuals' future responses to sleep deprivation. This strategy would be useful in operational settings with structured training programs during which the trait could be measured, such as the military. In other operational settings, however, this may not be practicable.

Another approach for the prediction of performance impairment due to sleep loss at the level of individuals involves the use of biomathematical models of fatigue and performance ${ }^{48)}$. A Bayesian forecasting technique ${ }^{49)}$ has been developed to tailor the parameters of such models to a given individual ${ }^{50)}$, so as to account for the individual's specific vulnerability to sleep loss and other relevant characteristics (e.g., sleep need, circadian phase). The technique depends on closed-loop feedback of measured performance to improve the individualized prediction of future performance; the underlying principles are sketched in Fig. 5. The method is particularly suitable for confined environments such as the cabin of a truck or the flight deck of a plane. These settings can be equipped for embedded performance measurement, that is, fully integrated extraction of performance measures from the primary job task (such as driving or flying), so that normal operations can continue without interruption. Examples of embedded performance measures include lane deviation in driving ${ }^{51)}$ and metrics drawn from flight operational quality assurance (FOQA) in commercial aviation. Because Bayesian forecasting has great potential for deployment in real-world operations, it has undergone rapid further technical development ${ }^{52-54)}$. The applicability is currently limited primarily by the limitations of available biomathematical model of fatigue and performance ${ }^{55,56)}$, which await inclusion of predictive equations for the effects of fatigue countermeasures ${ }^{57}$.

\section{Conclusion}

Although monitoring and selection of individuals for specific tasks or occupations can be fraught with ethical and legal complications, when done judiciously it can help to improve operational performance and productivity, reduce errors, incidents and accidents, increase worker satisfaction and well-being, and save lives. In the United States, employment selection (discrimination) based on genetic predictors of vulnerability (predisposition) to performance impairment is prohibited by the Genetic Information Nondiscrimination Act (GINA) of 2008. However, selection or restriction processes and targeted interventions based on actual performance observations or tests are, at least in principle, legally acceptable. It is important, though, to consider the possibility that individual differences in performance impairment may not 


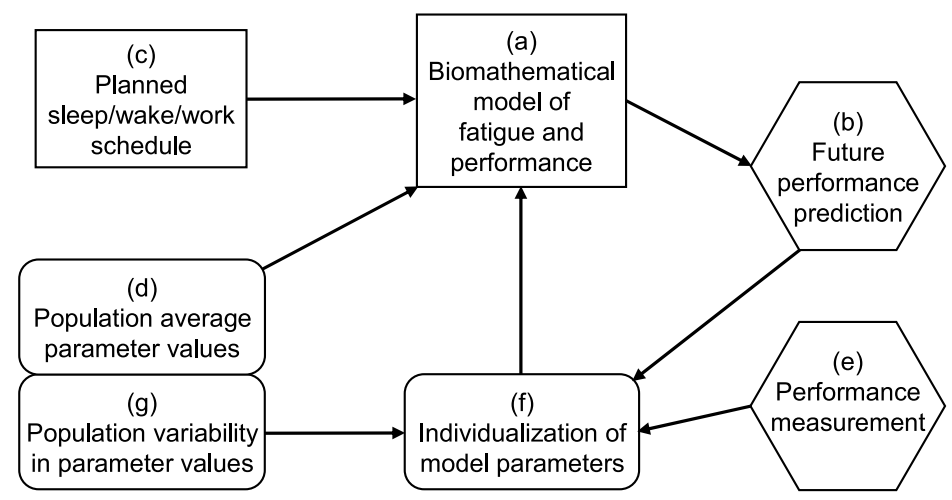

Fig. 5. Bayesian forecasting technique for individualized prediction of performance impairment during extended work hours and shift work schedules. The method makes use of a biomathematical fatigue model (a) to make predictions of future performance impairment (b) given a planned sleep/wake (and work) schedule (c). When applied to an individual whose vulnerability to performance impairment due to sleep loss and other relevant characteristics are not known in advance, performance predictions are based initially on population-average values for the model parameters (d). The predictions are later compared to measured actual performance (e), and any discrepancy is used to make corrections to the model parameters to better fit the individual (f). In order to distinguish individual traits from measurement noise and other sources of random variability, the comparison between predicted and actual performance is statistically referenced against the individual difference distributions of the model parameters in the population $(\mathrm{g})$, which are referred to as Bayesian priors. (The population averages and individual variabilities would typically be derived from some study of a sample of the population.) After individualization of the model parameters (f), the updated biomathematical model (a) is reapplied to make new predictions for subsequent performance (b). In a closed-loop procedure, these new prediction are later compared to actual performance (e) again. Any discrepancy leads to further individualization of the model parameters (f), which thereby gradually converge to the values that best describe the individual ${ }^{50)}$. The resulting model parameters for the individual can also be recorded for later use, so that during another exposure to extended hours or shift work, tailored performance predictions can be made right away.

generalize from one performance task to another (see above). Thus, performance tests and fitness-for-duty tests, even when performed during extended or shifted work hours as may be required by the occupational setting, may not accurately reveal a person's vulnerability or resilience with regard to the job at hand ${ }^{19)}$.

The prevalence of extended work and shift schedules in today's 24/7 economy, combined with long commutes and other demands on people's time, restricts the time available for sleep ${ }^{58)}$ and jeopardizes safety and productivity. That said, the 24/7 economy also offers unique opportunities to individuals who are relatively little affected by sleep loss and/or circadian effects ${ }^{19)}$. Assuming they are qualified, we would be well served to task them with our most safety-sensitive operations at night and in the early hours of the morning (or while flying across time zones), while others catch up on much needed sleep. In this context, the increasing recognition of the importance of individual differences in responses to extended work hours and shift work schedules should strengthen the case for replacing the rigidity of hours of service regulations by the flexibility of modern fatigue risk management strategies ${ }^{59)}$.

\section{Acknowledgements}

We gratefully acknowledge the steady support of David Dinges in our research on individual differences in vulnerability to performance impairment due to sleep loss, and the fruitful collaboration with John Caldwell and Lynn Caldwell. This research has been supported by the National Institutes of Health, Air Force Office of Scientific Research, United States Army Medical Research and Materiel Command, and NASA.

\section{References}

1) Wilkinson RT (1961) Interaction of lack of sleep with 
knowledge of results, repeated testing, and individual differences. J Exp Psychol 62, 263-71.

2) Webb WB, Levy CM (1984) Effects of spaced and repeated total sleep deprivation. Ergonomics 27, 45-58.

3) Gillberg M, Åkerstedt T (1985) Individual differences in susceptibility to sleep loss. In: VII International Symposium on Night- and Shiftwork, Haider M, Koller M and Cervinka R (Eds.), 117-22, Peter Lang, Igls.

4) Van Dongen HPA, Dijkman MV, Maislin G, Dinges DF (1999) Phenotypic aspect of vigilance decrement during sleep deprivation. Physiologist 42, A-5.

5) Leproult R, Colecchia EF, Berardi AM, Stickgold R, Kosslyn SM, Van Cauter E (2003) Individual differences in subjective and objective alertness during sleep deprivation are stable and unrelated. Am J Physiol Regul Integr Comp Physiol 284, R280-90.

6) Van Dongen HPA, Rogers NL, Dinges DF (2003) Sleep debt: theoretical and empirical issues. Sleep Biol Rhythms 1, 5-13.

7) Monk TH, Folkard S (1985) Individual differences in shiftwork adjustment. In: Hours of work: temporal factors in work-scheduling, Folkard S and Monk TH (Eds.), 227-37, John Wiley \& Sons, Chichester.

8) Härmä M (1993) Individual differences in tolerance to shiftwork: a review. Ergonomics 36, 101-9.

9) Costa G (2003) Shift work and occupational medicine: an overview. Occup Med 53, 83-8.

10) Härmä M (1995) Sleepiness and shiftwork: individual differences. J Sleep Res 4 (Suppl 2), 57-61.

11) Van Dongen HPA (2006) Shift work and inter-individual differences in sleep and sleepiness. Chronobiol Int 23, 1139-47.

12) Van Dongen HPA, Baynard MD, Maislin G, Dinges DF (2004) Systematic interindividual differences in neurobehavioral impairment from sleep loss: evidence of trait-like differential vulnerability. Sleep 27, 423-33.

13) Åkerstedt T, Gillberg M (1990) Subjective and objective sleepiness in the active individual. Int $\mathrm{J}$ Neurosci 52, 29-37.

14) Dinges DF, Powell JW (1985) Microcomputer analyses of performance on a portable, simple visual RT task during sustained operations. Behav Res Meth Instr Comp 17, 652-5.

15) Rupp TL, Wesensten NJ, Bliese PD, Balkin TJ (2009) Banking sleep: realization of benefits during subsequent sleep restriction and recovery. Sleep 32, 311-21.

16) Daan S, Beersma DGM, Borbély AA (1984) Timing of human sleep: recovery process gated by a circadian pacemaker. Am J Physiol 246, R161-78.

17) Dijk DJ, Czeisler CA (1994) Paradoxical timing of the circadian rhythm of sleep propensity serves to consolidate sleep and wakefulness in humans. Neurosci Lett 166, 63-8.

18) Van Dongen HPA, Dinges DF (2005) Sleep, circadian rhythms, and psychomotor vigilance. Clin Sports Med 24, 237-49.

19) Van Dongen HPA, Vitellaro KM, Dinges DF (2005)
Individual differences in adult human sleep and wakefulness: leitmotif for a research agenda. Sleep 28, 479-96.

20) Duffy JF, Rimmer DW, Czeisler CA (2001) Association of intrinsic circadian period with morningness-eveningness, usual wake time, and circadian phase. Behav Neurosci 115, 895-9.

21) Mongrain V, Lavoie S, Selmaoui B, Paquet J, Dumont M (2004) Phase relationships between sleep-wake cycle and underlying circadian rhythms in morningnesseveningness. J Biol Rhythms 19, 248-57.

22) Kerkhof GA, Van Dongen HPA (1996) Morning-type and evening-type individuals differ in the phase position of their endogenous circadian oscillator. Neurosci Lett 218, 153-6.

23) Breithaupt H, Hildebrandt G, Döhre D, Josch R, Sieber U, Werner M (1978) Tolerance to shift of sleep, as related to the individual's circadian phase position. Ergonomics 21, 767-74.

24) Folkard S, Hunt LJ (2000) Morningness-eveningness and long-term shiftwork tolerance. In: Shiftwork in the 21st century: challenges for research and practice, vol. 17, Hornberger S, Knauth P, Costa G and Folkard S (Eds.), 311-6, Peter Lang, Frankfurt am Main.

25) Morgan BB, Winne PS, Dugan J (1980) The range and consistency of individual differences in continuous work. Hum Factors 22, 331-40.

26) Roth T, Roehrs T, Rosenthal L (1997) Daytime sleepiness in normals: individual differences in sleep need not ability to fall asleep. In: Sleep and sleep disorders: from molecule to behavior, Hayaishi $\mathrm{O}$ and Inoue $\mathrm{S}$ (Eds.), 163-75, Academic Press, Tokyo.

27) Van Dongen HPA, Caldwell JA, Caldwell JL (2006) Investigating systematic individual differences in sleepdeprived performance on a high-fidelity flight simulator. Behav Res Meth 38, 333-43.

28) Mu Q, Mishory A, Johnson KA, Nahas Z, Kozel FA, Yamanaka K, Bohning DE, George MS (2005) Decreased brain activation during a working memory task at rested baseline is associated with vulnerability to sleep deprivation. Sleep 28, 433-46.

29) Goldstein A, Warren R, Kaizer S (1965) Psychotropic effects of caffeine in man. I. Individual differences in sensitivity to caffeine-induced wakefulness. J Pharmacol Exp Ther 149, 156-9.

30) Rétey JV, Adam M, Gottselig JM, Khatami R, Dürr R, Achermann P, Landolt H-P (2006) Adenosinergic mechanisms contribute to individual differences in sleep deprivation-induced changes in neurobehavioral function and brain rhythmic activity. J Neurosci 26, 10472-9.

31) Bodenmann S, Xu S, Luhmann UFO, Arand M, Berger W, Jung HH, Landolt HP (2009) Pharmacogenetics of modafinil after sleep loss: catechol-O-methyltransferase genotype modulates waking functions but not recovery sleep. Clin Pharmacol Ther 85, 296-304.

32) Mitler MM, O'Malley MB (2005) Wake-promoting 
medications: efficacy and adverse effects. In: Principles and practice of sleep medicine, 4th ed., Kryger $\mathrm{MH}$, Roth T and Dement WC (Eds.), 484-98, Elsevier Saunders, Philadelphia.

33) Takeyama H, Itani T, Tachi N, Sakamura O, Suzumura H (2002) Psycho-physiological effects of naps during night shifts on morning types and evening types. J Occup Health 44, 89-98.

34) Åkerstedt T, Ficca G (1997) Alertness-enhancing drugs as a countermeasure to fatigue in irregular work hours. Chronobiol Int 14, 145-58.

35) Stokes DE (1997) Pasteur's quadrant-basic science and technological innovation, Brookings Institution Press, Washington, D.C.

36) Wilkinson RT (1974) Measuring the effects of environment upon performance. Proc R Soc Med 67, 994-6.

37) Mitler MM, Miller JC, Lipsitz JJ, Walsh JK, Wylie CD (1997) The sleep of long-haul truck drivers. New Engl J Med 337, 755-61.

38) Bliese PD (2006) Age and individual variability in performance during sleep restriction. J Sleep Res 15, 376-85.

39) Orr WC, Martin RJ, Imes NK, Rogers RM, Stahl ML (1979) Hypersomnolent and nonhypersomnolent patients with upper airway obstruction during sleep. Chest 75, 418-22.

40) Gottlieb DJ, Whitney CW, Bonekat WH, Iber C, James GD, Lebowitz M, Nieto FJ, Rosenberg CE (1999) Relation of sleepiness to respiratory disturbance index: the sleep heart health study. Am J Respir Crit Care Med 159, 502-7.

41) Caldwell JA, Smith JK, Caldwell JL, Brown DL, Mu Q, Mishory A, Peters G, George MS (2005) Are individual differences in fatigue vulnerability related to baseline differences in cortical activation? Behav Neurosci 119, 694-707.

42) Van Dongen HPA (2005) Brain activation patterns and individual differences in working memory impairment during sleep deprivation. Sleep 28, 386-8.

43) Landolt HP (2008) Genotype-dependent differences in sleep, vigilance, and response to stimulants. Curr Pharm Des 14, 3396-407.

44) von Schantz M (2008) Phenotypic effects of genetic variability in human clock genes on circadian and sleep parameters. J Genet 87, 513-9.

45) Rétey JV, Adam M, Khatami R, Luhmann UFO, Jung HH, Berger W, Landolt HP (2007) A genetic variation in the adenosine $\mathrm{A} 2 \mathrm{~A}$ receptor gene (ADORA2A) contributes to individual sensitivity to caffeine effects on sleep. Clin Pharmacol Ther 81, 692-8.

46) Rétey JV, Adam M, Honegger E, Khatami R, Luhmann UFO, Jung HH, Berger W, Landolt HP (2005) A functional genetic variation of adenosine deaminase affects the duration and intensity of deep sleep in humans. Proc Nat Acad Sci 102, 15676-81.

47) Viola AU, Archer SN, James LM, Groeger JA, Lo JCY, Skene DJ, von Schantz M, Dijk DJ (2007) PER3 poly- morphism predicts sleep structure and waking performance. Curr Biol 17, 613-8.

48) Hursh SR, Van Dongen HPA (2009) Fatigue and performance modeling. In: Principles and practice of sleep medicine, 5th Ed., Kryger MH, Roth T and Dement WC (Eds.), in press, Elsevier Saunders, Philadelphia.

49) Olofsen E, Dinges DF, Van Dongen HPA (2004) Nonlinear mixed-effects modeling: individualization and prediction. Aviat Space Environ Med 75, A134-40.

50) Van Dongen HPA, Mott CG, Huang JK, Mollicone DJ, McKenzie FD, Dinges DF (2007) Optimization of biomathematical model predictions for cognitive performance impairment in individuals: accounting for unknown traits and uncertain states in homeostatic and circadian processes. Sleep 30, 1129-43.

51) Ingre M, Åkerstedt T, Peters B, Anund A, Kecklund G (2006) Subjective sleepiness, simulated driving performance and blink duration: examining individual differences. J Sleep Res 15, 47-53.

52) Kan K, Mott CG, Van Dongen HPA, Huang JK, Mollicone DJ, Dinges DF (2009) Individualizing performance predictions across sleep-wake transition. Aviat Space Environ Med 80, 217.

53) Mott CG, Van Dongen HPA, Kan K, Dinges DF, Huang JK, Mollicone DJ (2009) Optimizing individual performance predictions in real time under noisy conditions using particle filter Bayesian estimation. Aviat Space Environ Med 80, 217.

54) Smith AD, Genz A, Freiberger DM, Belenky G, Van Dongen HPA (2009) Efficient computation of confidence intervals for Bayesian model predictions based on multidimensional parameter space. Methods Enzymol 454, 213-31.

55) Dinges DF (2004) Critical research issues in development of biomathematical models of fatigue and performance. Aviat Space Environ Med 75, A181-91.

56) Van Dongen HPA (2004) Comparison of mathematical model predictions to experimental data of fatigue and performance. Aviat Space Environ Med 75, A15-36.

57) Balkin TJ, Kamimori GH, Redmond DP, Vigneulle RM, Thorne DR, Belenky G, Wesensten NJ (2004) On the importance of countermeasures in sleep and performance models. Aviat Space Environ Med 75, A155-7.

58) Basner M, Fomberstein KM, Razavi FM, Banks S, William JH, Rosa RR, Dinges DF (2007) American Time Use Survey: sleep time and its relationship to waking activities. Sleep 30, 1085-95.

59) Dawson D, McCulloch K (2005) Managing fatigue: it's about sleep. Sleep Med Rev 9, 365-80.

60) Borbély AA, Achermann P (1999) Sleep homeostasis and models of sleep regulation. J Biol Rhythms 14, 557-68.

61) Van Dongen HPA, Maislin G, Dinges DF (2004) Dealing with inter-individual differences in the temporal dynamics of fatigue and performance: importance and techniques. Aviat Space Environ Med 75, A147-54. 